2019-09-11

\title{
Delivering Energy Savings for the Supply Chain Through Building Information Modelling as a Result of the Horizon 2020 Energy BIMcert Project
}

\author{
Barry McAuley \\ Technological University Dublin, barry.mcauley@tudublin.ie \\ Avril Behan \\ Technological University Dublin, avril.behan@tudublin.ie
}

Follow this and additional works at: https://arrow.tudublin.ie/schmuldistcon

Part of the Civil Engineering Commons, Construction Engineering and Management Commons, Environmental Engineering Commons, and the Other Engineering Commons

\section{Recommended Citation}

McAuley, B., Behan, A., McCormack, P., Hamilton, A., Rebelo, E., Neilson, B., Beckett, G., Costa, A. A., Carreira, P., Likar, D., Taneva-Veshoska, A., Lynch, S., Hynes, W., Borkovic, T (2019) Delivering Energy Savings for The Supply Chain Through Building Information Modelling as a Result of The Horizon2020 Energy Bimcert Project. In: Scott, L. and Gorse, C. (Eds.) Procs 5th Annual SEEDS Conference, 11-12 September 2019, Ipswich, UK. doi:10.21427/z3w3-8m40

This Conference Paper is brought to you for free and open access by the School of Multidisciplinary Technologies at ARROW@TU Dublin. It has been accepted for inclusion in Conference papers by an authorized administrator of ARROW@TU Dublin. For more information, please contact arrow.admin@tudublin.ie, aisling.coyne@tudublin.ie,gerard.connolly@tudublin.ie.

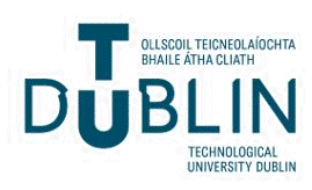




\title{
DELIVERING ENERGY SAVINGS FOR THE SUPPLY CHAIN THROUGH BUILDING INFORMATION MODELLING AS A RESULT OF THE HORIZON2020 ENERGY BIMCERT PROJECT
}

\author{
${ }^{1}$ Barry McAuley, ${ }^{1}$ Avril Behan, ${ }^{2}$ Paul McCormack, ${ }^{2}$ Andrew Hamilton, \\ ${ }^{2}$ Eduardo Rebelo, ${ }^{3}$ Barry Neilson, ${ }^{3}$ Gayle Beckett, ${ }^{4}$ António Aguiar Costa, \\ ${ }^{5}$ Paulo Carreira, ${ }^{6}$ Dijana Likar, ${ }^{6}$ Angelina Taneva-Veshoska, ${ }^{7}$ Sheryl Lynch, \\ ${ }^{7}$ William Hynes and ${ }^{8}$ Toni Borkovic
}

\author{
${ }^{1}$ School of Multidisciplinary technologies, Technological University Dublin, Bolton Street, Dublin \\ 1, Ireland. \\ ${ }^{2}$ Belfast Metropolitan College, e3 Building, 398 Springfield Road, Belfast, Northern Ireland. \\ ${ }^{3}$ CITB Northern Ireland, Nutts Corner Training Centre, 17 Dundrod Road, Crumlin, County Antrim, \\ Northern Ireland. \\ ${ }^{4}$ CERIS, Department of Civil Engineering, Architecture and Georesources, Instituto Superior Técnico, \\ Universidade Lisboa, Av. Rovisco Pais, 1049-001 Lisboa, Portugal. \\ ${ }_{5}^{5}$ iNESC-ID Lisboa, Rua Alves Redol, 9 1000-029 Lisboa, Portugal \\ ${ }^{6}$ Institute for Research in Environment, Civil Engineering and Energy (IECE), Drezdenska, No.52, Skopje, \\ R. Macedonia 1000. \\ ${ }^{7}$ Future Analytics Consulting Ltd, 23 Fitzwilliam Square, Ireland. \\ ${ }^{8}$ Energy Institute Hrvoje Pozar, Savska cesta 163, 10001 Zagreb, Croatia.
}

\begin{abstract}
The global buildings sector is now responsible for $40 \%$ of final energy consumption as well as accounting for $33 \%$ of energy-related carbon dioxide emissions. This has resulted in a growing urgency to address energy and emissions from buildings and construction, to meet restrictive 2020 targets as specified by the European Union (EU). To achieve these targets a number of funding initiatives have been put in place through Horizon 2020 with a focus on BIM, due to it having the potential to rapidly produce energy outputs that enable design teams to analyse and compare the most cost-effective, energy-efficient options. However, despite the recorded benefits that BIM can bring to the design, there is still a lack of understanding of how it can be used on site by the supply chain to impact energy savings directly. In order to address this industry-wide concern a Multi-International consortium, bid, won and then launched the Horizon 2020 Energy BIMcert project in March 2018 with the goal to educate all areas of the supply chain in the use of BIM, so as to achieve better energy efficiency during the design, construction and ongoing maintenance of an asset. An online platform will be launched in September 2019, which will deliver blended training that combines theory, practice, and eLearning that will enable workers to train more effectively. This paper will explore the initial stages of this project and will focus on how the findings from a survey and series of workshops conducted within the member states of the Energy BIMcert consortium has helped establish the training needs of the industry. These findings were cross-referenced with a state-of-the-art literature review on BIM pedagogy, which has resulted in the formation of the curriculum and learning outcomes for a number of BIM focused training units. Further to this, the paper will discuss how the delivery of the blended training and associated materials will affect current energy saving targets.
\end{abstract}

Keywords: building information modelling, Sustainability, Education, Horizon 2020

\subsection{INTRODUCTION}

The exploitation and utilisation of energy resources have caused severe ecological and environmental problems, including the production of emissions that contribute to global 
warming (Enshassi et al., 2018). The construction industry consumes up to $50 \%$ of mineral resources excavated from nature, generates about $33 \%$ of $\mathrm{CO} 2$ present in the atmosphere and is responsible for $40 \%$ of total global energy through both construction and operational emissions (Ajayi et al., 2016 and Zhou and Azar, 2018). This has resulted in the AEC Sector, out of necessity, been forced to investigate new methods of practice and how best to apply resource-efficient techniques from the extraction of the raw materials to the demolition and disposal of its components.

The realisation that practices now face globalization, sustainability, and environmental concerns, as well as ever-changing legislation requirements and new skills needed for the information age, has resulted in technologies such as Building Information Modelling (BIM) becoming a key enabler in navigating these concerns (Jaradet, 2014). BIM can be defined as a modelling technology and associated set of processes to produce, communicate, and analyze building models (Sacks et al., 2018). BIM provides an opportunity for the Architectural, Engineering, Construction, and Operation (AECO) industry stakeholders to evaluate possible solutions and identify potential problems of the final product before the start of actual construction (Badrinath et al., 2016).

However, changing from traditional practices to BIM requires a shift not only in the technology used but also in the way design and construction teams work together (Shelbourn et al., 2017). To achieve the associated benefits that are accustomed to BIM, a number of existing challenges to Information and communications technology (ICT) utilisation in construction site management must be overcome, which include a lack of knowledge, skills and competence, depth of understanding of decision makers and low ICT literacy (Ozumba and Shakantu, 2017). This BIM movement has also resulted in a clear, direct, and automatic impact upon engineering education systems (Jäväjä and Salin, 2014).

To assist in overcoming these barriers, so as to reach EU energy-related targets a number of funding initiatives have been put in place through Horizon 2020 with a focus on BIM, as a result of it having the potential to rapidly produce energy outputs that enable design teams to analyse and compare the most cost-effective, energy-efficient options. Such an initiative is the Energy BIMcert project, which aims to educate all areas of the supply chain in the use of BIM, to achieve better energy efficiency during the design, construction and ongoing maintenance of an asset.

\subsection{ENERGY BIMCERT BACKGROUND}

Horizon 2020 is the biggest ever EU Research and Innovation programme, with nearly $€ 80$ billion of funding available over seven years (2014 to 2020). An initial funding call, as part of this programme, was made available with a focus on supporting innovation through research by way of demonstration of more energy-efficient technologies and solutions. The Energy BIMcert consortium, consisting of industry and academia who are experts in 
providing BIM solutions, skills and training for the construction industry, backed up by a Technical Advisory Board of stakeholders and external experts, responded to the call. The consortium put forward a proposal to enable the development of a method, materials and micro accreditation for upskilling across the construction supply chain to allow BIM techniques and technologies to be utilised to address energy efficiency requirements.

Energy BIMcert's goal is to develop more efficient and relevant training programme materials that integrate concepts of sustainability and renewables with practical application and integration with technology, as based on real-life industry needs and limitations. The Energy BIMcert consortium consisting of members from Northern Ireland (Belfast Metropolitan College and Construction Industry Training Board (CITB)), Republic of Ireland (Technological University (TU) Dublin and Future Analytics), Portugal (Universidade Lisboa), Macedonia (Institute for Research in Environment, Civil Engineering and Energy (IECE)), and Croatia (Energy Institute Hrvoje Pozar (EIHP)) established five core objectives:

1. To improve the sustainability of the built environment by training its workforce in more efficient and greener ways of designing and constructing through the use of BIM processes, better materials, products, and energy sources;

2. To engage with the entire construction sector supply chain via BIM to develop more extensive European links and to encourage a system of peer support across states of varying maturity concerning the delivery of more energy efficient new and renovated buildings;

3. To encourage greater workforce mobility, continuous upskilling, and better employability for all levels of an employee in the construction sector;

4. To create clear pathways of development for individuals and SMEs to upskill from any starting point of knowledge to any required level of the individual, or collaborative expertise, in support of sustainable energy efficient construction; and

5. To develop a pan-European framework for recognition and accreditation of Energy BIMcert's micro accredited learning modules, that will combine to build towards fully standardised skills recognition, linking within existing national and European initiatives and frameworks of accredited courses and awards.

The consortium established a series of work packages which are to be conducted in five stages:

- STAGE 1 - State of the Art: An open approach to gather state of the art information through direct engagement with project stakeholders across Europe to ensure that the skills gaps identified by SMEs about the implementation of BIM technologies and methods in support of improved energy efficiency in the construction sector are correct.

- STAGE 2 -Development: Development of the Energy BIMcert platform, which will provide information about the project, share Energy BIMcert outputs, and support stakeholders' communication and collaboration.

- STAGE 3 - Testing: The rigorous evaluation of the curriculum, the learning materials, and the proposed platform. 
- STAGE 4 - Accreditation: Accreditation of the proposed Energy BIMcert training units and courses.

- STAGE 5 - Exploitation and Dissemination: The exploitation and dissemination of the project through a broad-ranging outreach campaign.

This paper will focus on Stage 1 with the final four stages outside of scope.

\subsection{METHODOLOGY}

The consortium has established a detailed and exhaustive process in determining the training methodologies and associated curriculum. An initial pan European wide survey of the industry was undertaken to ascertain the current level of BIM maturity, knowledge and understanding within Built Environment practitioners and academia and to establish current standards of sustainable design and construction practice. The results from the survey have been cross-referenced with five workshops within the project stakeholders' jurisdictions. The results from the survey and workshops were used to establish the training courses that best-matched industry needs. In parallel, TU Dublin completed a state-of-the-art literature review of the current global status of BIM regarding education and what pedagogical methodologies are applied to deliver these courses. The survey and workshop findings were cross-referenced with the results from the state-of-the-art literature review in the production of a rolling Matrix of Concepts and Methodologies aligned to best practice for knowledge transfer. Both the initial findings for the suggested training courses and Matrix of Concepts and Methodologies have been tested through a series of Reality Check workshops. The outcomes from the Reality Check workshops resulted in the establishment of the final training methodologies, descriptors including learning outcomes, suggested syllabi, and delivery details.

\subsection{STATE OF THE ART}

Stage 1 will be broken down into four sections; 1) Energy BIMcert Survey and Workshops 2) Concepts and Methodologies 3) Reality Check Workshops and 4) Curriculum and Materials.

\subsection{Energy BIMcert Survey}

A survey was undertaken in all five partner countries by CITB, which was subsequently translated into four languages, resulting in 548 responses. The breakdown of the survey response is illustrated in figure 1 . To validate the findings, a total of five workshops took place with stakeholders between the $2^{\text {nd }}$ May and $6^{\text {th }}$ June 2018 , which were used to gather supplement data to cross-reference with the survey results. The workshops were open to the industry, and representatives of the advisory partners were strongly encouraged to attend. The results found that all respondents recognised that BIM training is required at all levels within their organisations. The survey findings indicate that $57 \%$ of respondents have received no formal BIM training, despite $61 \%$ using some form of BIM in the workplace. A further $53 \%$ of survey respondents indicated they were prepared to implement BIM within the next three years, of those $26 \%$ aim to achieve this within the next 12 months. The two main challenges identified within the survey and reiterated at the workshops, as most critical were a) Lack of BIM skills (46\%) and b) Lack of Client awareness of the value of BIM (43\%). 


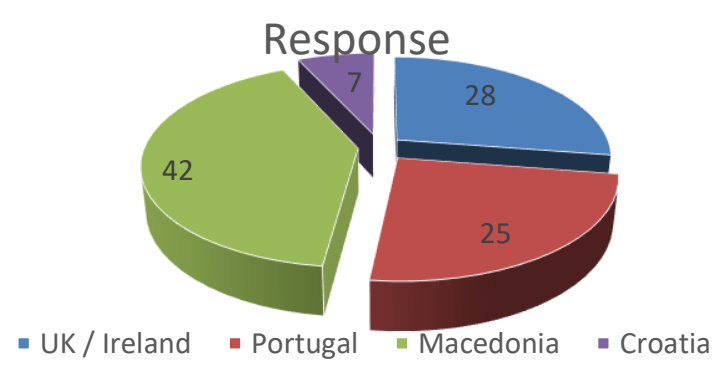

Figure 1: Response by Country

Regarding training, 53\% of respondents indicated they would prefer a person led course with practical demonstrations, while the other $47 \%$ reported they would prefer online training. Based on the workshop consultations, Energy BIMcert coordinators noticed a discrepancy between industry knowledge and enthusiasm for adopting BIM. The results show that government encouragement for BIM adoption, particularly within the UK and Republic of Ireland was a strong motivating factor. A lack of Government endorsement within Macedonia and to a lesser extent, Croatia, has resulted in them facing similar concerns to those discussed above.

The results highlighted the necessity to raise awareness of BIM as a sophisticated, sustainable, supportive software, not only for modelling and visualisation tools but furthermore by developing training modules to facilitate the trend. The lack of BIM maturity within some of the partner's jurisdictions' informed the consortium that if potential users were going to understand how BIM is used for energy-related proposes that they would need a fundamental understanding of the core principles, as well as how to access information for review purposes. These findings influenced the consortium in the selection of training courses discussed later in the paper.

\subsection{BIM Concepts and Methodologies}

TU Dublin undertook a state-of-the-art literature review of current BIM teaching initiatives that represent best practice for knowledge transfer. The report identified many potential training methodologies that could be applied to the Energy BIMcert platform. The proposed methods include Problem Project Based Learning (PBL) which is recognized as a capable student-centered pedagogical approach focusing on real-world issues, which allows students to build knowledge and to develop critical thinking, creativity, leadership, and communication (Badinrath et al. 2016). The PBL approach is fully supported for the software elements of BIM and is widely used in engineering and construction management education to build the ideal scaffold to student learning for sustainable living (Wu and Luo, 2016). The option of Narrative videos and in-house video tutorials are also robust learning tools as they enable the student the opportunity to self-learn (Adamu and Thorpe, 2016). The use of narrative videos to teach BIM has become a prevalent theme over the last number of years. Guided Self-Study (GSL) is one of the best ways to facilitate professional development concerning BIM through self-training with continuous peer support and ad-hoc internal workshops (Puolitaival and Forsyth, 2016). 
Other training methodologies examined include Web-based tutorials which are a combination of media, that allows the user to control, combine, and manipulate different types of mediums of communication such as text, graphics, still images, and interactive features (Guy, 2013). Web-based tutorials work in tandem with Instructor-led tutoring, which can involve giving step-by-step instructions to students, in a virtual or physical class. Instructor-led tutoring has been the most common BIM tutoring approach in AEC degree programs (Abdirad \& Dossick, 2016). The authors also endorse the use of Case Studies as tools to enable students to learn and think about real-world challenges and solutions as well as standards and conventions in BIM implementation. Design for Disassembly (DFD) could be applied to any of the discussed methodologies as it involves the process of designing products so that they can be easily, cost-effectively and rapidly taken apart at the end of the product's life so that components can be reused and recycled. Badinrath et al. (2016) explain that through focusing at the issues surrounding sustainable design through an investigation into DFD, one can have a stronger appreciation.

Mastery Learning and Scaffolding Learning approaches were explored as further possible learning methodologies. Mastery learning requires the students to master a more straightforward subject before moving on to the next, more complex one (Shelbounre et al.,2017). The authors also discuss Scaffolding Learning which involves taking steps to reduce the student's degrees of freedom in carrying out some tasks so that the learner can concentrate on the problematic skill they are in the process of acquiring. Other teaching tools and methodologies suggested to the Energy BIMcert consortium included active learning, where both the educator and learners cooperate in formulating and achieving a combined experience whereby the learner has an active role. There is evidence that dynamic learning experiences can enhance the learning of collaborative BIM concepts (Becker et al., 2011). The flipped classroom which is an instructional strategy and a type of blended learning that reverses the traditional learning environment by introducing the learning material before class, with classroom time then being used to deepen understanding through discussion with peers and problem-solving activities facilitated by teachers. The application of role play can also enable the potential user to gain an understanding of other professional's roles and therefore provide a greater understanding of the importance of data.

The results from this exercise were cross-referenced with the survey and workshop results to ensure that the selected methodology was industry appropriate. Figure two provides a matrix of the most suitable concepts and methodologies that best align with the Energy BIMcert survey, workshops, and findings from the pedagogical and methodologies literature review. Based on this diagram and further cross-reference of the literature review the most suitable approach would involve a Scaffolded Learning approach, as users requested a step by step method delivered trough instructor-led live lecture which would limit the degrees of freedom to ensure a structured approach (Shelbourne et al.,2017 and Abdirad \& Dossick 2016). On further review of Figure 2 and the literature, this would be best complimented through providing an intelligent student-centered pedagogical approach focusing on realworld issues (PBL) along with self-training and continuous peer support (GSL). This could be achieved by surrounding the student with a sustainable design through an investigation into DFD (Puolitaival and Forsyth, 2016 and Badrinath et al. 2016). However, this may prove difficult due to the nature of the project, and a more blended approach may need to be 
adopted. This could involve the inclusion of pre-recorded Narrative videos to enable the student the opportunity to self-learn, that could be complemented through live lectures to ensure they still have a base to communicate with the lecturer. This would enable a structured pathway for users to move from Scaffolded to Masterly Learning where the user is required to critically understand a topic through a combination of GSL and PBL before moving on to the next area of interest (Adamu and Thorpe, 2016 and Shelbourne et al.2017).

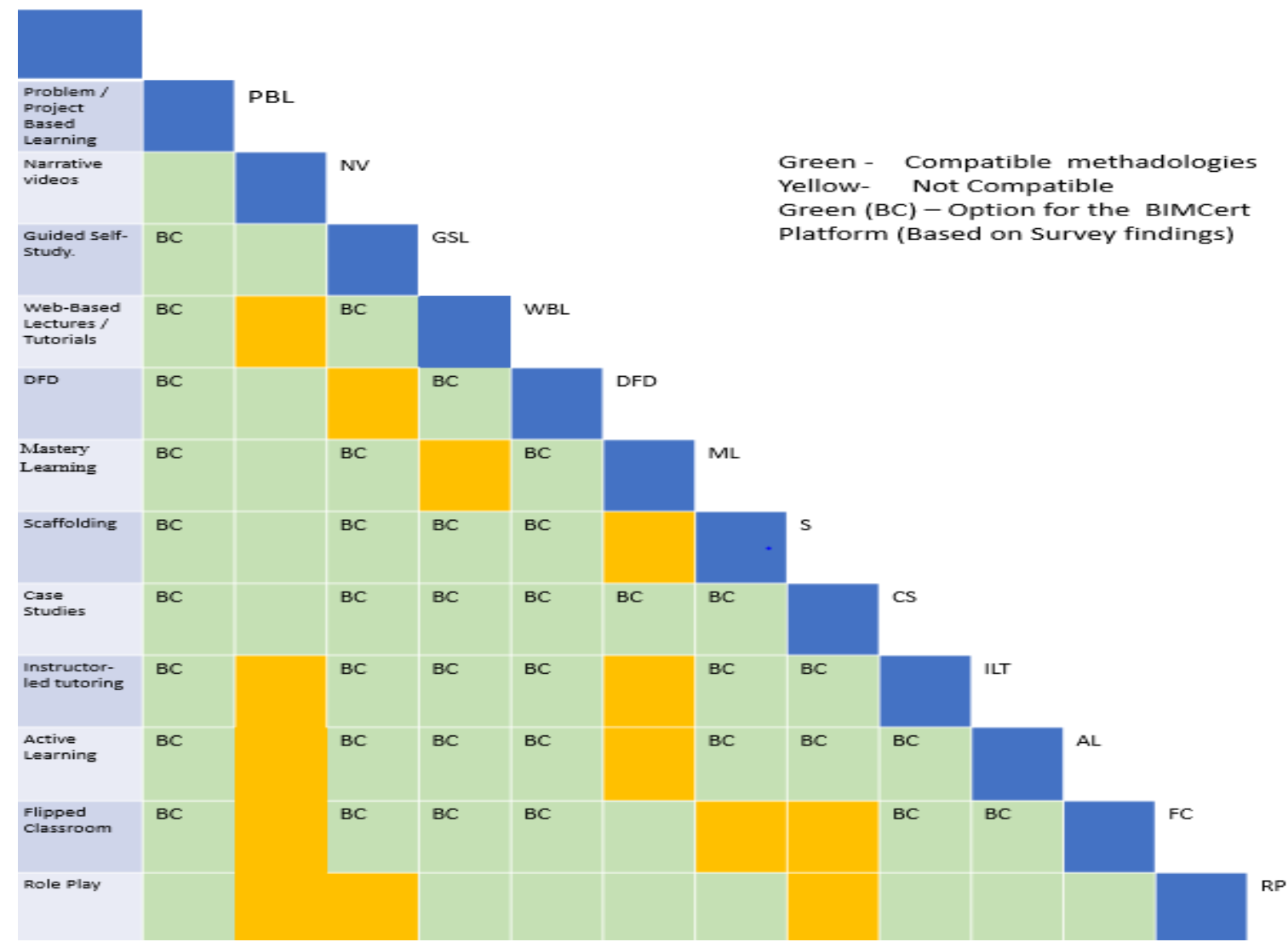

Figure 2: Matrix of Concepts and Methodologies

\subsection{Energy BIMcert Reality Check Workshops}

FAC and CITB carried out five trial Workshops within the consortiums jurisdictions with key stakeholders to test the suggested curriculum and concepts and methodologies. The workshops were hosted both within the partner city bases and online. The purpose of the workshop was to establish if the current curriculum and methodologies were adequate. The workshop also aimed to develop a knowledge base of BIM awareness on a European level and a rationale for the emerging trends in the reports carried out by CITB and how this would impact the reception of the Energy BIMcert on a national and broader European level.

Before the commencement of the Workshops project leads, Belfast Metropolitan College developed the outline for a potential training unit titled BIM Ready. This training unit is aimed at complete novices within the area and explores the drivers, enablers, requirements, benefits, and barriers associated with BIM. They will also briefly be introduced to BIM concepts, principles, maturity levels, key terms, and standards. The learner will also gain a 
general understanding of BIM for low energy construction. It was the intention for BIM Ready to be made available to the learner when they initially access the BIMcert portal. The consortium aimed to develop more focused training units on the drivers and enablers of BIM once the learner had progressed through BIM Ready.

In all of the partner countries, BIM was recognised not only as a modelling software but as a sustainability support tool for energy efficient and green construction. Throughout the trials, the top five findings were:

1. BIM awareness and skill varies hugely from country to country;

2. Some Contractors are reluctant to invest in BIM (Need for evidence-based case studies of BIM cost-effectiveness);

3. There is a reluctance to engage with IT as a medium for learning;

4. The BIM supply chain is congested (mostly confined to management); and

5. Energy BIMcert is a positive and viable enabler/facilitator of BIM upskilling.

The favored learning styles that emerged through the workshops were the blended learning option with self-selection of the micro-sized learning courses. Taking into account the results of the Energy BIMcert Survey and workshops, and given that the platform will be online, the primary methodology suggested of a scaffolded learning environment guided by a series of instructor-led live lectures gained favor. However, a more blended approach involving narrative videos and live lectures which would assist in reducing the requirement of a lecturer and put more focus on the student doing GSL through PBL and DFD before they advance to the next digital badge was also warmly received. The Concept of the BIM Ready training unit was endorsed, with a recognition that one must gain an understanding of the fundamentals of BIM before they fully appreciate how it can be applied to save energy. Recommendations for the development of further training material in this space were requested, with an active request for courses in working in digital construction, associated workflows, digital skills for construction sites and low energy building construction.

\subsection{Development of Curriculum and Materials}

The development of curriculum and associated materials involved TU Dublin, Belfast Metropolitan College, and IECE working in partnership. While this was ongoing Universidade Lisboa was in contact to ensure that the final platform was suitable to host the potential curriculum. EIHP were also busy continuing to promote the project through established dissemination channels, as well as endorsing the project through the website domain (https://energybimcert.eu). The consortium members decided that the best way forward was to break the development of the curriculum into three strides. The term "stride" was used to avoid confusion with terms such as "level," "stage," and "point," which all have other associated meaning in the BIM Terminology of different EU jurisdictions. Figure 3 identifies the units and courses that best reflect the needs of the industry from the consultation process.

The Learner initially accesses the BIMcert portal and will be presented with one of two options. If the learner selects Option A, then they must take the BIM Ready training unit plus online assessment. Successful completion of the assessment grants access to Stride 2 . 
This entry unit is critical to ensuring that all learners have a basic understanding of BIM before they select their next unit within Stride 2. The BIM Ready unit is also vital here as it will serve as a diagnostic tool to assist the leaner in the selection of the next unit. Those who complete BIM Ready will be able to use their assessment marks to automatically pass some of the learning outcomes within the training units offered in Stride 2 . This will encourage users to undertake a full unit. Entry Option B is aimed at non-novices and permits the learner to take an online assessment directly.

- Learner accesses the BIMCert portal.

- Stride 1: option A: Learner takes BIM Ready plus online assessment; successful entry grants access to Stride 2.

- Stride 10 ption B: Learner directly takes online assessment; successful entry automatically grants entry to Stride 2 . Final Unit of BIM Ready assists the learner in the selection of the next module. Appropriate to their needs / roles.

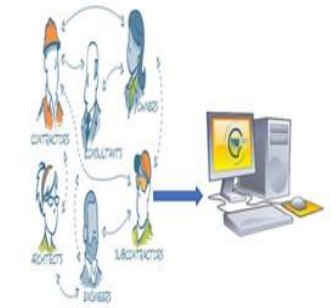

- Stride 2A: Learner selects a stand alone Unit aimed at BIM novices.

- Stride 2B:Learner selects a stand alone Unit aimed at those professionals with a deeper BIM knowledge.

- Stride 2C: Learner selects a course (c) which contains a number of units. Successful completion of relevant units will enable learners access to advanced modules.

- Stride 3: Specialist modules to be developed

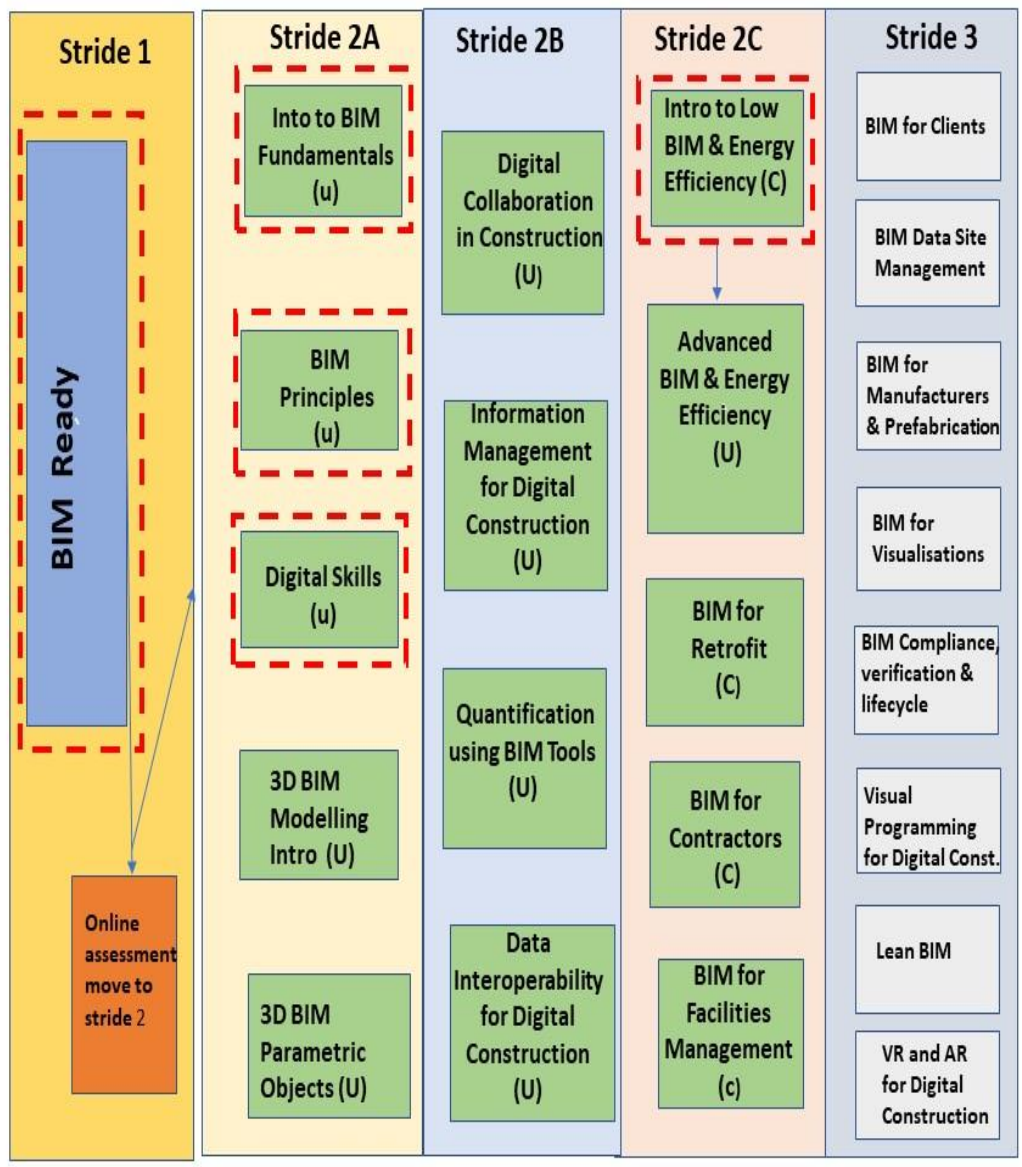

Figure 3 BIMcert Learning Pathways

It was agreed to break Stride 2 into three separate sections. Within Stride $2 \mathrm{~A}$, the learner can select many standalone units that will introduce them to BIM principles, digital skills, and modelling techniques. The following training units have been developed, as part of stride $2 \mathrm{~A}$ in response to the survey and workshops findings.

- Introduction to BIM Fundamentals: This training unit will enable the learner to develop a fundamental understanding of the Information Technology skills required for working within digital construction, i.e., understand their role and others within the digital construction sector, list the benefits and value of a BIM workflow and define the role of BIM in achieving improved sustainable construction.

- Introduction to BIM Principles: This training unit will enable the learner to develop a fundamental understanding of BIM and associated workflows, i.e., understand the context and essentials of BIM, detail the application and standards of BIM and define the technological requirements for BIM implementation and security. 
- Digital Skills: This training unit will enable the learner to develop a fundamental understanding of the use of digital skills for construction sites, i.e., describe the use of digital skills and devices in construction, demonstrate the use of digital tools to perform a design review and evaluate a BIM model, etc.

- 3D BIM Modelling: This training unit will enable the learner to develop the fundamental skills for three dimensional (3D) BIM using industry standard software for their particular profession i.e. define how BIM may be used within the construction and design industry, create a building model using industry-standard BIM software, implement and manage BIM and develop and publish information using BIM.

- 3D BIM (Parametric) Objects: This training unit will enable the learner to develop the fundamental skills to create BIM objects using industry standard software, i.e., demonstrate the importance and use of parametric objects in digital construction, generate templates, design and create BIM, export, insert and use BIM objects.

Stride $2 \mathrm{~B}$ represents units aimed at those more experienced BIM users who wish to advance their knowledge in BIM, e.g., interoperability, collaboration processes, etc. While learning outcomes are developed for these training units, it is not the intention of the Energy BIMcert consortium to develop them any further during this iteration of the Horizon 2020 project. Stride $2 \mathrm{C}$ offers the learners the choice of one or more courses, which consists of a series of units. Each unit within a course represents a specific Learning Outcome. This Learning Outcome / Unit will be offered as an individual micro size training option, to ensure that the Energy BIMcert can attract learners who require specific areas of knowledge but do not have the time to complete a standard unit (Stride $2 \mathrm{~A}$ and $2 \mathrm{~B}$ ) consisting of a series of learning outcomes. After completion of all units associated with the course, the learner will receive a higher award. The learner can take advanced units once they finish the relevant Stride $2 C$ course units, i.e., Advanced BIM \& Energy Efficiency. As with Stride $2 B$, it is not the intention of the consortium to develop all of the courses in this stride. The consortium aims to develop the Introduction to Low Energy Building Construction course, which will contain some units that will provide an understanding of sustainable and energy efficient design and how to apply them. Stride 3 represents a more discipline-focused stride that represents current specialisations of BIM usage, tools, and concepts. The range of units can be expanded or adjusted in the next stage of the project in response to market needs.

A variety of material from a selection of learning outcomes from the BIM Ready (Stride 1), BIM Fundamentals (Stride 2A), BIM Principles (Stride 2A), Digital Skills (Stride 2A), and Introduction to Low Energy Building Construction Course (Stride $2 \mathrm{C}$ ) will be developed for testing in Phase 2 of the project. The Energy BIMcert consortium selected these particular learning units because they have the potential to impact significant numbers of construction site workers across Europe rapidly. The selected material can also be delivered through instructor-led live lectures which will enable the opportunity for the lecturer/trainer to engage with the class. It is also the attention to develop material that can be used for GSL to gain an insight into how potential users would interact with this material. Results from the testing of the pilot materials from the second round of partner trial workshops can found in McAuley et al. (2019). 


\subsection{CONCLUSION}

The paper has discussed how the Energy BIMcert initiative can assist in improving the sustainability of the built environment by training of its workforce in more efficient and greener ways of designing and constructing through the use of BIM processes. The proposed Energy BIMcert platform will provide a direct response to a perceived lack of available micro-sized training units and will cater for all levels of BIM knowledge within the industry. While better energy awareness and sustainable building practices are at the core of the project the consortium have recognised that a diverse workforce will require a fundamental understanding of BIM principles if they are to fully embrace and engage with the capabilities associated with digital construction. This approach is fully supported by industry who continue to demonstrate an appetite for BIM. The next stage of the project is the piloting and evaluation of material through a series of Workshops across the consortiums Jurisdictions. These Workshops will enable the refinement of the content before being released on the final BIMcert Training platform before the final phase of testing.

\subsection{REFERENCES}

Abdirad, H. and Dossick, C. (2016) BIM Curriculum Design in Architecture, Engineering, and Construction Education: A Systematic Review, Journal of Information Technology in Construction, ITcon, Vol. 21 (2016), pg. 250

Aghaegbuna Obinna U. Ozumba, À. O.U. and Shakantu, W. (2017) Exploring challenges to ICT utilisation in construction site management, Construction Innovation, Vol. 18 Issue: 3 pp 1471-4175

Ajayi, S.O. Oyedele, L.O. Kadiri, K.O. Akinade, O.O., Bilal, M., Owolabi, H.A. and Alaka, H.A. (2016) Competency-based measures for designing out construction waste: task and contextual attributes, Engineering, Construction and Architectural Management, Vol. 23 Issue: 4, pp.464-490

Badrinath, A.C., Chang, Y.T and Hsieh, S. H. (2016) A review of tertiary BIM education for advanced engineering communication with visualization, Visualization in Engineering, Iss 4:9, pp 2-17

Becker, T., Jaselskis, E. and McDermott, C. (2011). Implications of Construction Industry Trends on the Educational Requirements for Future Construction Professionals. International Conference Proceedings of the 47th Associated Schools of Construction, Omaha, Nebraska, United States, 6-9th April, pp 1-12

Enshassi, A., Ayash, A. and Mohamed, S. (2018) Factors driving contractors to implement energy management strategies in construction projects, Journal of Financial, Management of Property and Construction, Vol. 23 Issue: 3, pp.295-311

Guy, R. and Lownes-Jackson, M. (2013) Web-based tutorials and traditional face-to-face lectures: a comparative analysis of student performance, Informing Science and Information Technology, Vol. 10, pp.241-259.

Jäväjä, P. and Salin, j. (2014) BIM Education: Implementing and Reviewing "OpeBIM" - BIM for Teachers, Proceedings of the Computing in Civil and Building Engineering, Orlando, Florida, June 23-25, pp $2151-2158$

Jaradat, S. (2014) Educating the Next Generation of Architects for Interdisciplinary BIM Environments, Proceedings of the AAE International Conference on Architectural Education: common currency, University of Sheffield - 3rd to 5th September, pp 127-135 
McAuley, B., Behan, A., McCormack, P., Hamilton, A., Rebelo, E., Neilson, B., Beckett, G., Costa, A.A., Carreira, P., Likar, D., Taneva-Veshoska,A., Lynch, S., Hynes, W. and Borkovic, T. (2019) Improving the Sustainability of the Built Environment by Training its Workforce in More Efficient and Greener Ways of Designing and Constructing Through the Horizon2020 Energy BIMcert Project, Proceedings of the CitA BIM Gathering, Galway 26th -27th September, pp 1-8.

Puolitaival, T. and Forsythe, P. (2016) Practical challenges of BIM education, Structural Survey, Vol. 34 Issue: 4/5, pp.351-366

Sacks, R., Eastman, E., Lee, G. and Teicholz, P. (2018) BIM Handbook: A Guide to Building Information Modeling for Owners, Designers, Engineers, Contractors, and Facility Managers, John Wiley \& Sons Inc

Shelbourn, M., Macdonald, J., McCuen, T. and Lee, S. (2017) Students perceptions of BIM education in the higher education sector a UK and USA perspective, Industry and Higher Education, 31 (5). pp. 293-304.

Wu, W. and Luo, Y. (2016). Pedagogy and assessment of student learning in BIM and sustainable design and construction, ITcon, Vol. 21, pg. 218-232

Zhou, H. and Azar, E. R. (2018) BIM-based energy consumption assessment of the onsite construction of building structural systems, Built Environment Project and Asset Management, Vol. 9 Issue: 1, pp.2-14, 